\title{
Comparative Hemodynamic Effects of Levosimendan Alone and in Conjunction with 4-Aminopyridine or Calcium Chloride in a Rodent Model of Severe Verapamil Poisoning
}

\author{
Andis Graudins $•$ Kathy Ka Ling Wong
}

Published online: 15 May 2010

(C) American College of Medical Toxicology 2010

\begin{abstract}
Levosimendan (Levo) increases sensitivity of troponin-C to calcium, thus increasing myocardial contractility. It is also a vascular $\mathrm{K}+$-ATP channel agonist producing peripheral vasodilation. Previous research with levosimendan revealed an increase in cardiac output (CO) but not blood pressure (BP) in experimental verapamil poisoning. Levosimendan's K+-channel agonist properties may augment verapamil's vasodilatory effects. 4Aminopyridine (4-AP) is a $\mathrm{K}+$-channel antagonist. It has successfully reversed hypotension in experimental verapamil poisoning. We hypothesized that coadministration of these agents may improve $\mathrm{BP}$ and $\mathrm{CO}$ in verapamil poisoning. Anesthetized, ventilated, and canulated male Wistar rats were poisoned with verapamil. Animals received one of six treatments, which are as follows: (1) n-saline infusion (control), (2) Levo $6.25 \mu \mathrm{g} / \mathrm{kg}$ loading dose and $36 \mu \mathrm{g} / \mathrm{kg} / \mathrm{h}$ infusion, (3) 4-AP $2 \mathrm{mg} / \mathrm{kg}$ loading dose and infusion (4-AP), (4) Levo+4-AP, (5) $\mathrm{CaCl}_{2}$ loading dose and infusion, and (6) Levo $+\mathrm{CaCl}_{2}$. Hemodynamic parameters were recorded for $60 \mathrm{~min}$. Outcome measures were changes in $\mathrm{CO}, \mathrm{BP}$, and heart rate $(\mathrm{HR})$
\end{abstract}

Levosimendan donated for research purposes by Abbott Australasia, Pty Ltd.

A. Graudins $(\bowtie)$

Clinical and Experimental Toxicology Unit,

Department of Emergency Medicine, Prince of Wales Hospital,

Barker Street,

Randwick, NSW, Australia 2031

e-mail: andis.graudins@monash.edu

A. Graudins $\cdot$ K. K. L. Wong

Prince of Wales Clinical School and School of Medical Sciences,

Faculty of Medicine, University of New South Wales,

Kensington, NSW, Australia compared to control. All groups had similar pretoxicity and peak toxicity $\mathrm{CO}(50 \%$ of pretoxicity value), BP $(50 \%$ or pretoxicity value), and HR. Control group $\mathrm{CO}, \mathrm{BP}$, and $\mathrm{HR}$ progressively dropped during the verapamil infusion. Levosimendan produced a statistically significant improvement in $\mathrm{CO}$ (75\% of pretoxicity level) but not BP in comparison to control. 4-AP produced a significant improvement in CO (110\% of pretoxicity) and BP (78\% of pretoxicity). Levo $+4-\mathrm{AP}$ and $\mathrm{Levo}+\mathrm{CaCl}_{2}$ groups improved CO (100\% of pretoxicity) and BP $(77 \%$ and $50 \%$ of pretoxicity, respectively), but there was no additive increase in $\mathrm{CO}$ or $\mathrm{BP}$ in animals compared to 4- $\mathrm{AP}$ or $\mathrm{CaCl}_{2}$ alone. Levosimendan moderately improved $\mathrm{CO}$ but not $\mathrm{BP}$ in verapamil poisoning. The hypotensive effects of levosimendan were not overcome by coadministration of either 4-AP or $\mathrm{CaCl}_{2}$. Levosimendan may not be an appropriate agent to use in the treatment of verapamil poisoning.

Keywords Poisoning - Overdose $\cdot$ Calcium channel blockers · Verapamil · Levosimendan · Aminopyridine . Rodent

\section{Introduction}

Verapamil is regarded as potentially the most toxic of the calcium-channel-blocking agents in overdose, producing both negative inotropic and chronotropic effects on the myocardium as well as peripheral vasodilatation with resultant severe hypotension from a combination of reduced cardiac output and fall in systemic vascular resistance. To date, there has been no single antidotal agent that reliably reverses shock in verapamil poisoning. Patients often require more than one agent to maintain blood pressure. 
This may include a combination of inotropic and pressor drugs to produce a positive hemodynamic response. Levosimendan (Levo) is a novel cardiac inotropic agent that exerts its effects by sensitizing troponin-C to calcium, thus increasing myocardial contractility without increasing intracellular calcium and adenosine triphosphate concentrations or myocardial oxygen demand $[1,2]$. It also possesses mild inhibitory actions on phosphodiesterase-III and relaxes peripheral vascular smooth muscle by agonism of vascular smooth muscle potassium channels [3]. As a result, levosimendan increases cardiac output and reduces after load. These effects may be beneficial in other forms of heart failure. Given the effects of levosimendan on modulation of myocardial calcium, we theorized that it may be a useful agent in reversal of verapamil-induced cardiac toxicity and have previously reported on the effects of this agent in a rodent model of verapamil poisoning [4]. Levosimendan produces a moderate but significant improvement in cardiac output in verapamil poisoned rats but does not result in a concomitant rise in systemic blood pressure suggesting that its vasodilatory properties may antagonize any benefits seen in improvement in cardiac output. Additionally, the coadministration of other potentially vasoactive agents with levosimendan, such as calcium chloride and norepinephrine, do not improve blood pressure or result any additional increase in cardiac output compared either agent infused on its own $[4,5]$. As a result, we were unable to overcome the hypotension seen in verapamil poisoning despite moderate improvements in cardiac output seen with infusion of levosimendan. The current study aims to determine whether the administration of a specific $\mathrm{K}+$ channel antagonist in conjunction with levosimendan overcomes the lack of improvement in blood pressure seen when levosimendan is administered as a single agent in verapamil poisoned rodents. 4-Aminopyridine (4-AP) is a potent $\mathrm{K}+$-channel antagonist that has been shown to improve hemodynamic instability in experimental and in a small number of human cases of verapamil poisoning [6, 7]. This agent acts by an indirect influence on calcium channels. 4-AP blocks $\mathrm{K}^{+} 1$ potassium channels on the cytoplasmic side of the cellular membrane, blocking the efflux of intracellular potassium, resulting in depolarization of voltage-dependent calcium channels and influx of calcium into the cell [7].

\section{Method}

This was a randomized open-label study utilizing male adult albino Wister rats. Blinding was not performed as a single investigator performed the experiments once surgery was completed. The method was similar to that described previously [4].
Animals

Consent was obtained from the University of New South Wales Animal Care and Ethic Committee. Male adult albino inbred Wister rats ( 300 to $500 \mathrm{~g}$ ) were used to avoid problems associated with the oestrus cycle of the female rat.

\section{Pre-experiment Procedures}

Animals were anesthetized initially with halothane in an enclosed Perspex anesthesia box. Once unconscious, $120 \mathrm{mg} / \mathrm{kg}$ thiobutabarbital, a long-acting barbiturate agent, was intraperitoneally administered (Inactin, Sigma Chemicals, MO, USA). Before the start of surgical procedure, animals were administered $0.04 \mathrm{mg} / \mathrm{kg}$ fentanyl citrate (Mayne Pharma, Melbourne, Australia). Animals were placed on a heating pad and under a heating lamp to maintain body temperature between $36^{\circ} \mathrm{C}$ and $38^{\circ} \mathrm{C}$. The trachea was canulated, and the animals were ventilated $(10 \mathrm{ml} / \mathrm{kg}$ and 45 breaths per minute) using a Ugo Basile model 7025 Ventilator (Comerio, VA, Italy). The left carotid artery was canulated, and a MLT1402 T-type Ultra Fast Thermocouple probe (AD Instruments, Castle Hill, Australia) was passed through the canula for aortic blood temperature measurement for cardiac output estimation by the thermodilution technique. The left and right jugular veins were canulated with double lumen polyethylene catheters (North Rocks, Australia) for infusion of drugs and fluids. The left femoral artery was canulated with a single lumen polyethylene tubing (BD Diagnostics, Sparks, MD, USA) for arterial blood pressure monitoring via an ADInstruments MLT844 physiological pressure transducer and ML110 bridge amp (ADIstrusments, Castle Hill, Australia). A rectal temperature probe was inserted for tissue temperature monitoring. Cutaneous ECG electrodes were placed for single lead III recording of heart rate and rhythm. Continuous data collection for ECG, arterial blood pressure, and rectal and central temperature was performed using a PowerLab 4/30 data acquisition system and Chart Version 5.0 software (ADInstruments, Castle Hill, Australia). Cardiac output was estimated sequentially with the PowerLab cardiac output system and cardiac output Module Software (ADInstrument, Castle Hill, Australia). Briefly, $200 \mu$ l of cold Hartmann's solution was injected via the left internal jugular vein, and a thermodilution curve was recorded from the carotid thermistor probe on PowerLab Chart Software. Cardiac output was calculated using the area-under-the-curve by Cardiac Output Module found in PowerLab Chart Software. Cardiac output is reported in milliliters per minute per $100 \mathrm{~g}$. Average cardiac output for healthy rats is reported as $20-25 \mathrm{ml} / \mathrm{min} / 100 \mathrm{~g}$ [8].

Once surgery was completed, animals were allowed $30 \mathrm{~min}$ for equilibration. Prior to commencement of 
experiment baseline heart rate (HR), mean arterial blood pressure (MAP), systolic blood pressure (SBP), and cardiac output $(\mathrm{CO})$ were recorded. Hemodynamic parameters were then recorded at peak toxicity (time 0 ) and every $10 \mathrm{~min}$ during treatment for $1 \mathrm{~h}$ or until death. Two or sometimes three syringe pumps were used for drug infusion during the experiment (Graseby 3100; Terumo model STO 523). Animals were euthanized at the end of the experiment.

\section{Experimental Protocol}

Animals were administered verapamil hydrochloride (isoptin injection, $2.5 \mathrm{mg} / \mathrm{ml}$, purchased from Abbott Australasia) by continuous infusion of $6 \mathrm{mg} / \mathrm{kg} / \mathrm{h}$ until MAP fell to $50 \%$ of baseline (time 0 ). The verapamil infusion was then reduced to $4 \mathrm{mg} / \mathrm{kg} / \mathrm{h}$ to maintain toxicity. Once toxicity was established, HR, MAP, SBP, and CO were recorded, and animals were randomly assigned to one of six treatment groups (ten rats in each group).

The treatment groups were:

Group 1 (Control)

Rats received normal saline loading dose of $10 \mathrm{ml} / \mathrm{kg}$ infused over $10 \mathrm{~min}$ followed by normal saline infusion of $10 \mathrm{ml} / \mathrm{kg} / \mathrm{h}$ for $50 \mathrm{~min}$.

Group 2 (Levo)

Rats received levosimendan $6.25 \mu \mathrm{g} / \mathrm{kg}$ in $10 \mathrm{ml} / \mathrm{kg}$ of $\mathrm{n}$-saline as loading dose infused over $10 \mathrm{~min}$ followed by $36 \mu \mathrm{g} / \mathrm{kg} / \mathrm{h}$ as an infusion dose in $10 \mathrm{ml} / \mathrm{kg} / \mathrm{h} \mathrm{n}$-saline for $50 \mathrm{~min}$

\section{Group 3 (4-AP)}

Rats received $2 \mathrm{mg} / \mathrm{kg}$ loading dose of 4-aminopyridine over $10 \mathrm{~min}$ in $10 \mathrm{ml} / \mathrm{kg} \mathrm{n}$-saline followed by $2 \mathrm{mg} / \mathrm{kg} / \mathrm{h}$ in $10 \mathrm{ml} / \mathrm{kg} / \mathrm{h} \mathrm{n}$-saline for $50 \mathrm{~min}$.

Group 4 (Levo and 4-AP)

Rats received levosimendan loading dose of $6.25 \mu \mathrm{g} / \mathrm{kg} /$ $\min$ in $5 \mathrm{ml} / \mathrm{kg} \mathrm{n}$-saline and 4-aminopyridine loading dose of $2 \mathrm{mg} / \mathrm{kg} / \mathrm{min}$ in $5 \mathrm{ml} / \mathrm{kg} / \mathrm{h} \mathrm{n}$-saline over $10 \mathrm{~min}$. After this, levosimendan $36 \mu \mathrm{g} / \mathrm{kg} / \mathrm{h}$ and 4-aminopyridine infu- sion at $2 \mathrm{mg} / \mathrm{kg} / \mathrm{h}$ were each administrated in $5 \mathrm{ml} / \mathrm{kg} / \mathrm{h} \mathrm{n}$ saline for $50 \mathrm{~min}$.

\section{Group $5\left(\mathrm{CaCl}_{2}\right)$}

Rats received $0.2 \mathrm{mmol} / \mathrm{kg}$ loading dose of calcium chloride over $10 \mathrm{~min}$ in $10 \mathrm{ml} / \mathrm{kg} \mathrm{n}$-saline followed by $0.2 \mathrm{mmol} / \mathrm{kg} / \mathrm{h}$ in $10 \mathrm{ml} / \mathrm{kg} / \mathrm{h} \mathrm{n}$-saline for $50 \mathrm{~min}$.

\section{Group 6 (Levo and $\mathrm{CaCl}_{2}$ )}

Rats received levosimendan loading dose of $6.25 \mu \mathrm{g} / \mathrm{kg}$ in $5 \mathrm{ml} / \mathrm{kg} \mathrm{n}$-saline and calcium chloride loading dose at $0.2 \mathrm{mmol} / \mathrm{kg}$ in $5 \mathrm{ml} / \mathrm{kg} \mathrm{n}$-saline over $10 \mathrm{~min}$. After this, levosimendan $(36 \mu \mathrm{g} / \mathrm{kg} / \mathrm{h})$ and calcium chloride $(0.2 \mathrm{mmol} / \mathrm{kg} / \mathrm{h})$ were each administered in $5 \mathrm{ml} / \mathrm{kg} / \mathrm{h} \mathrm{n}$ saline for $50 \mathrm{~min}$.

Treatment protocols lasted a total of $60 \mathrm{~min}$. Ten minutes for loading dose followed by $50 \mathrm{~min}$ for maintenance infusion. HR, CO, SBP, and MAP were measured every $10 \mathrm{~min}$ for the duration of treatment. All animals received $10 \mathrm{ml} / \mathrm{kg}$ loading dose of fluid and $10 \mathrm{ml} / \mathrm{kg} / \mathrm{h}$ as an infusion with their respective treatments.

Data were analyzed and plotted graphically as mean \pm SEM for the variables every $10 \mathrm{~min}$ until the end of the 60 min treatment protocol or death using Graph Pad Prism Version 4.03 Software (GraphPad Software, Inc.).

\section{Statistical Method}

Continuous hemodynamic measures were examined using one-way analysis of variance and Dunnett's posttest comparing each treatment group to control. Mortality at 60 min was assessed by Fisher's exact test comparing each treatment groups to the control group. Results were considered statistically significant at $p<0.05$ (two-tailed). All statistical analyses were carried out using GraphPad InStat 3.01 statistical software (GraphPad Software, Inc.).

\section{Results}

Prior to the administration of verapamil, baseline SBP, CO, HR were similar in all groups (Table 1), and there was also

Table 1 Summary of baseline hemodynamic parameters prior to verapamil administration expressed as mean \pm SEM

\begin{tabular}{lccccrrr}
\hline$t=-10$ & Control & Levo & 4-AP & Levo+4-AP & \multicolumn{2}{c}{ Calcium } & \multicolumn{2}{c}{ Levo+Calcium } \\
\hline CO (ml/100 g) & $18.9 \pm 0.6$ & $19.2 \pm 0.9$ & $21.5 \pm 0.8$ & $19.2 \pm 1.2$ & $18.2 \pm 1.2$ & $20.4 \pm 0.9$ & NS \\
SBP (mmHg) & $158.4 \pm 3.1$ & $129.8 \pm 4.09$ & $148.6 \pm 6.5$ & $135.5 \pm 4.1$ & $139.6 \pm 7.2$ & $141.5 \pm 7.5$ & NS \\
HR (bpm) & $334.5 \pm 13.0$ & $345.3 \pm 11.8$ & $328.8 \pm 18.6$ & $336.5 \pm 10.3$ & $345.8 \pm 11.3$ & $358.0 \pm 6.8$ & NS \\
Weight (g) & $417.5 \pm 12.4$ & $386.8 \pm 8.7$ & $413.0 \pm 10.3$ & $415.4 \pm 7.6$ & $425.4 \pm 8.6$ & $401.8 \pm 11.8$ \\
\hline
\end{tabular}

$N S$ not significant 
Table 2 Summary of hemodynamic parameters at the time of peak toxicity $(t=0)$ expressed as mean \pm SEM

\begin{tabular}{|c|c|c|c|c|c|c|c|}
\hline$t=0$ & Control & Levo & 4-AP & Levo+4-AP & Calcium & Levo+Calcium & \\
\hline $\mathrm{CO}(\mathrm{ml} / 100 \mathrm{~g})$ & $8.3 \pm 1.2$ & $11.9 \pm 1.1$ & $13.8 \pm 1.4$ & $12.4 \pm 1.3$ & $11.4 \pm 1.1$ & $11.8 \pm 1.0$ & NS \\
\hline $\mathrm{SBP}(\mathrm{mmHg})$ & $58.4 \pm 3.1$ & $61.9 \pm 1.7$ & $61.5 \pm 4.3$ & $58.7 \pm 3.9$ & $56.3 \pm 4.4$ & $61.0 \pm 3.3$ & NS \\
\hline HR (bpm) & $304.8 \pm 23.6$ & $308.5 \pm 19.8$ & $313.3 \pm 12.5$ & $290.6 \pm 11.4$ & $286.2 \pm 20.2$ & $322.3 \pm 14.5$ & NS \\
\hline
\end{tabular}

$N S$ not significant

no significant difference in peak toxicity hemodynamic parameters (time 0) in all groups (Table 2). Animal weights were also comparable between groups.

\section{Survival}

Only four of ten $(40 \%)$ animals survived the protocol in control group. Death resulted from a combination of bradycardia and hypotension. In the group receiving calcium infusion, there was a $100 \%$ survival till the end of the experiment. This was statistically significant compared to control $(p=0.0108)$ by Fisher's exact test. The 4-AP and Levo $+\mathrm{CaCl}_{2}$ groups had survival in nine out of ten animals at $60 \mathrm{~min}(90 \% ; p=0.05$ vs control). The Levo and Levo+4AP groups showed survival in eight out of ten animals at $60 \mathrm{~min}(80 \%)$. This was not statistically significant compared to control for these two groups (Fig. 1).

Hemodynamic Effects of Levosimendan, 4-Aminopyridine, and Calcium Chloride

i) Response of cardiac output to treatment

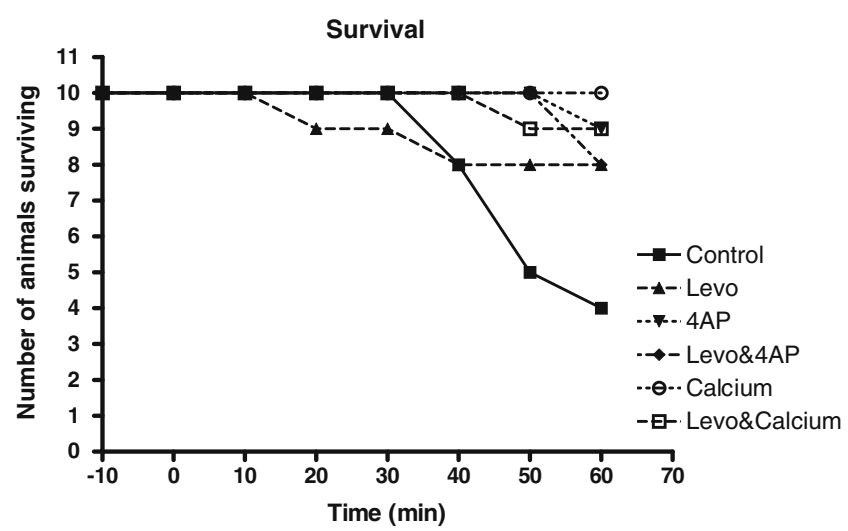

Fig. 1 Comparison of survival of animals in five treatment groups and control over the 60-min time course of study. Calcium chloride-treated group ( $p=0.012$ ) significant survival difference compared with control by Fisher's exact test. 4-Aminopyridine and levosimendan+calcium groups significant survival compared with control $(p=0.05)$. Levosimendan and 4-AP+levosimendan did not have statistically significant survival difference compared with control
Cardiac output was significantly higher than untreated control animals for all treatment groups (Fig. 2). The levosimendan treatment group showed a statistically significant improvement in cardiac output compared to control at $t=30$ and $40 \mathrm{~min}(p<0.05)$.

4-AP produced the most rapid improvement in cardiac output compared to control from $10 \mathrm{~min}$ after the start of the therapy $(p<0.01)$. Levo+4-AP and $\mathrm{CaCl}_{2}$ also produced a statistically significant improvement in cardiac output compared to control from $t=20 \mathrm{~min}$ onward $(p<0.01)$. Administration of $\mathrm{Levo}+\mathrm{CaCl}_{2}$ also resulted in an improvement in cardiac output compared to control particularly at the beginning of the treatment $(p<0.05$ at $10 \mathrm{~min}, p<0.01$ from $20 \mathrm{~min}$ onward). Analysis of area-under-the-curve data for the treatment groups compared to control also showed significant differences for all treatments (Table 3). Notably, there did not appear to be any additive improvement in $\mathrm{CO}$ with coadministration of levosimendan with the other agents.

\section{ii) Response of blood pressure to treatment}

Treatment with levosimendan resulted in no improvement in SBP in this study compared to control group. Blood pressure deteriorated progressively till the end of the experiment (Fig. 3). Treatment with 4-AP alone resulted in a statistically significant improvement in systolic blood pressure as compared to control group $(p<0.01)$ from $t=+10$ min until the end of the experiment. Levo $+4-\mathrm{AP}$ also produced a similarly statistically significant improvement in SBP $(p<0.01) . \mathrm{CaCl}_{2}$, in comparison to control group, also resulted in a significant improvement in SBP from $t=+10 \mathrm{~min}(p<0.05)$ although SBP did not return to pretoxicity levels. Treatment with $\mathrm{Levo}+\mathrm{CaCl}_{2}$ only produced a significant improvement in SBP at $t=30 \mathrm{~min}$ $(p<0.05)$ and $t=40 \mathrm{~min}(p<0.01)$. There was no additive effect on blood pressure with coadministration of levosimendan with the other agents.

\section{iii) Response of heart rate to treatment}

In the control group, a gradual decline in heart rate was observed (Fig. 4). Treatment with 4-AP maintained heart rate at the pretoxicity level compared to control throughout the period of verapamil poisoning at $t=+30 \mathrm{~min}(p<0.05)$ and $t=+40$ and $+60 \min (p<0.01)$. Levosimendan, Levo $+4-\mathrm{AP}$, 
Control vs Levo

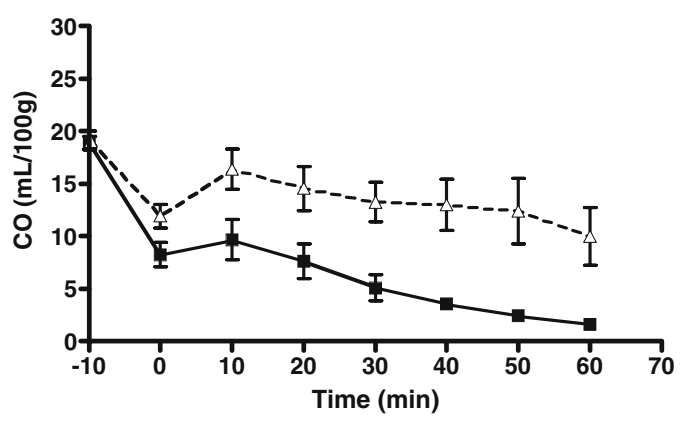

1. At $\mathrm{t}=-10,0,10,20,50$ and 60 , Control vs Levo not significant

2. At $\mathrm{t}=30$ and 40 , Control vs Levo $(\mathrm{P}<0.05)$

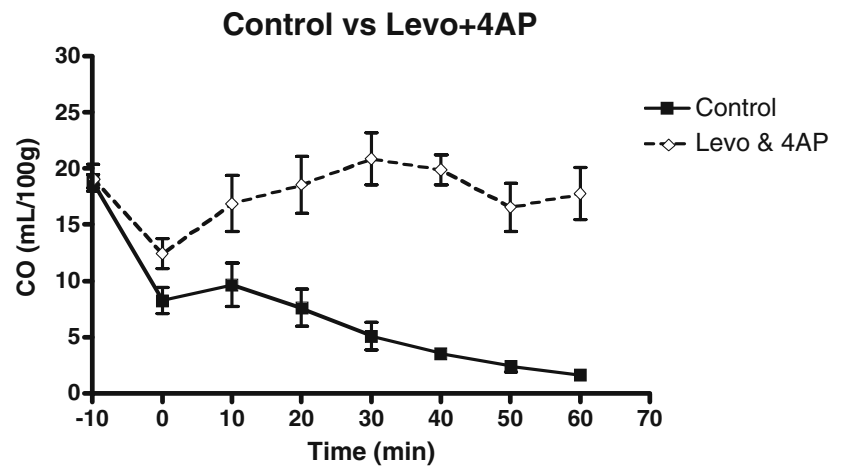

1. At $\mathrm{t}=-10,0$ and 10 , Control vs Levo+4AP not significant

2. At $\mathrm{t}=20,30,40,50$ and 60 , Control vs Levo+4AP $(\mathrm{P}<0.01)$

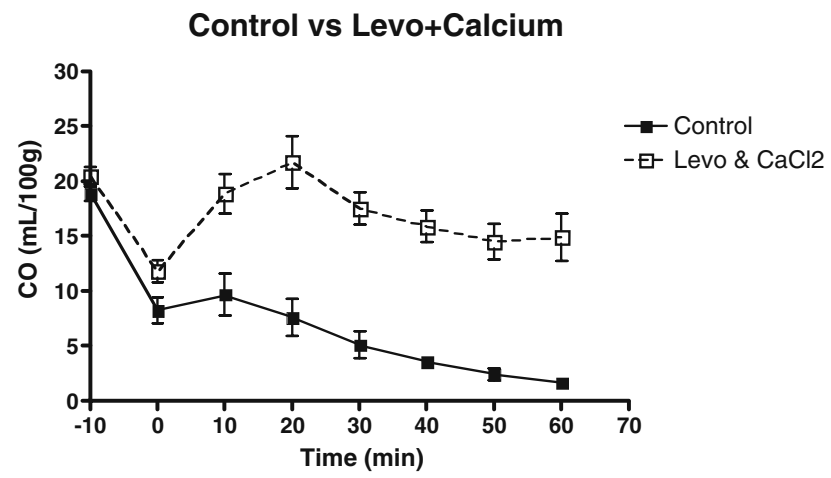

1. At $\mathrm{t}=-10$ and 0 , Control vs $\mathrm{Levo}+\mathrm{CaCl}_{2}$ not significant

2. At $\mathrm{t}=10,50$ and 60 , Control vs $\mathrm{Levo}+\mathrm{CaCl}_{2}(\mathrm{P}<0.05)$

3. At $\mathrm{t}=20,30$ and 40 , Control vs Levo $+\mathrm{CaCl}_{2}(\mathrm{P}<0.01)$

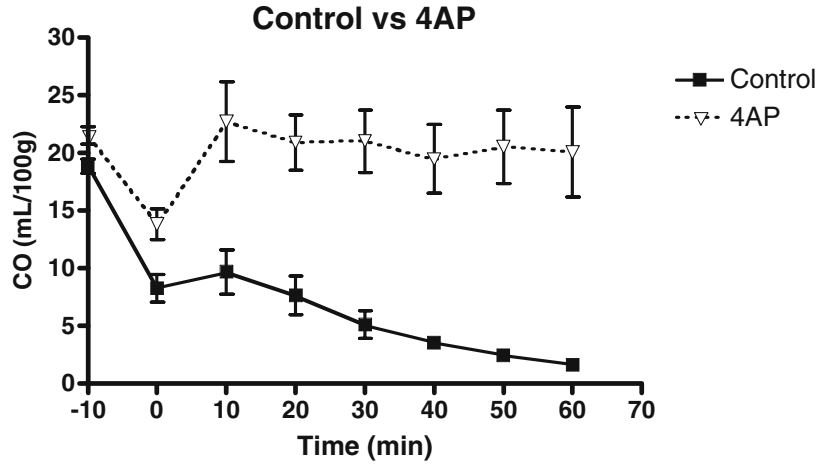

1. At $\mathrm{t}=-10$ and 0 , Control vs $4 \mathrm{AP}$ not significant

2 At $\mathrm{t}=10,20,30,40,50$ and 60, Control vs 4AP $(\mathrm{P}<0.01)$

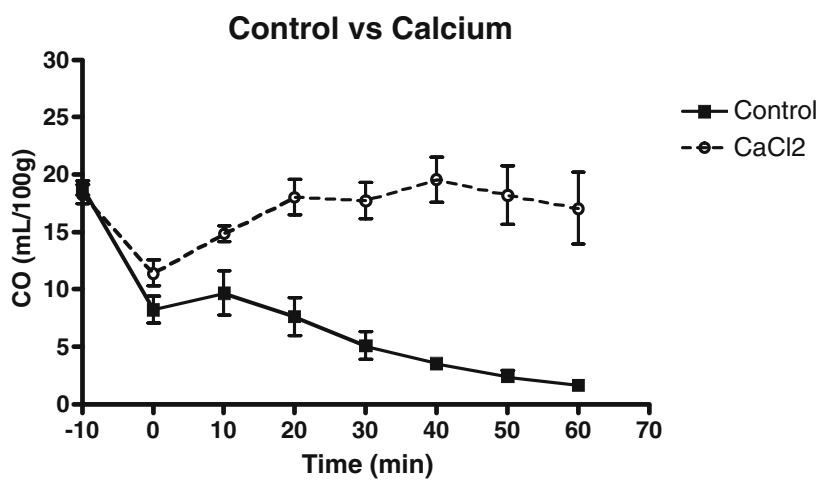

1. At $\mathrm{t}=-10,0$ and 10 , Control vs $\mathrm{CaCl}_{2}$ not significant

2. At $\mathrm{t}=20,30,40,50$ and 60 , Control vs $\mathrm{CaCl}_{2}(\mathrm{P}<0.01)$

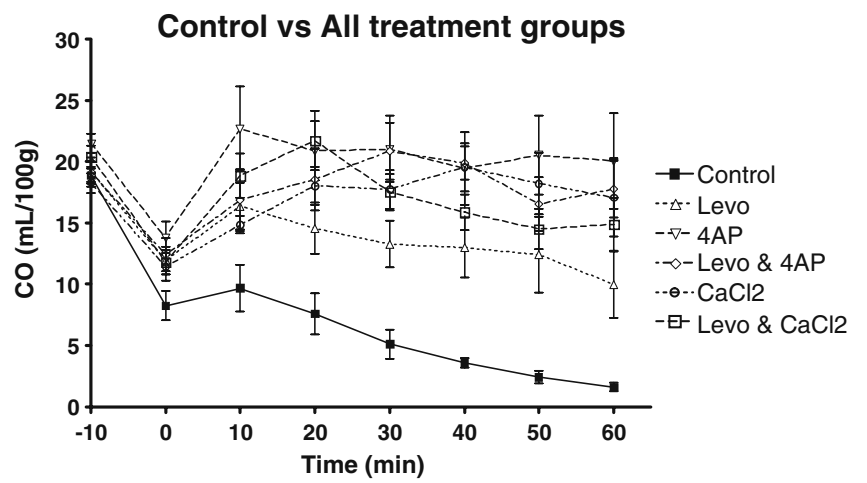

Fig. 2 The effects of experimental treatments on cardiac output (mean+SEM) in rats intravenously poisoned with verapamil

Table 3 A comparison of cardiac output area-under-the-curve for animals in each of the treatment groups compared with control

\begin{tabular}{lrrrrrr}
\hline & Control & \multicolumn{1}{l}{ Levo } & 4-AP & Levo+4-AP & $\mathrm{CaCl}_{2}$ & $\mathrm{Levo}^{2} \mathrm{CaCl}_{2}$ \\
\hline Mean AUC (ml/h/100 g) & 420 & 861 & 1,356 & 1,210 & 1,084 \\
$95 \%$ CI & $296-543$ & $589-1,132$ & $996-1,717$ & $1,012-1,408$ & $857-1,311$ & $949-1,360$ \\
\hline
\end{tabular}

All groups area-under-the-curve (AUC) significant compared with control $p<0.01$ except Levo, $p<0.05$ (Dunnett's posttest). Levo AUC also significantly less than 4-AP, $p<0.01$ (Dunnett's posttest) 


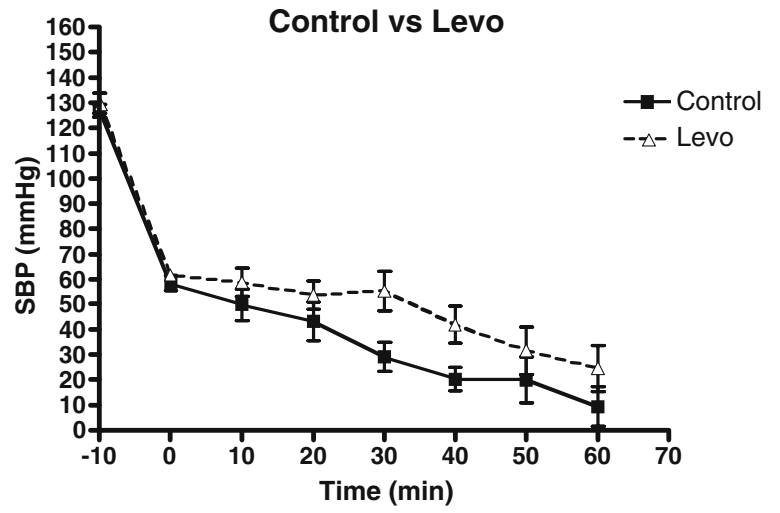

1. At $\mathrm{t}=-10,0,10,20,30,40,50$ and 60 , Control vs Levo not significant

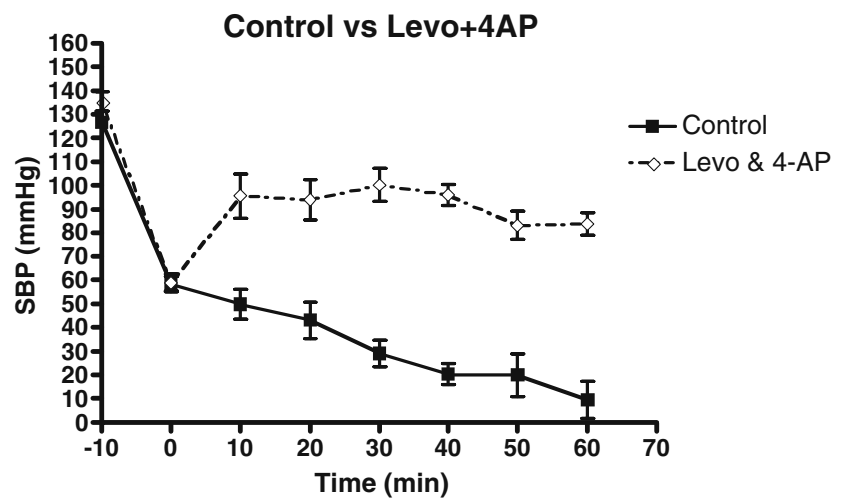

1. At $\mathrm{t}=-10$ and 0 , Control vs Levo+4AP not significant

2. At $\mathrm{t}=10,20,30,40,50$ and 60, Control vs Levo+4AP $(\mathrm{P}<0.01)$

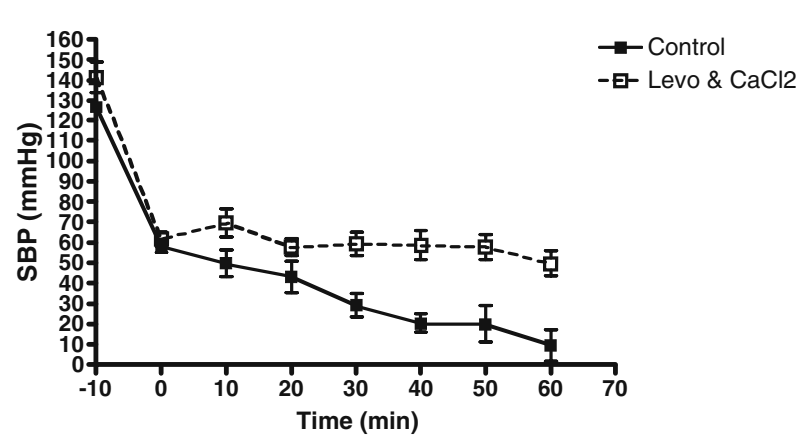

1. At $\mathrm{t}=-10,0,10,20,50$ and 60 , Control vs Levo+ $\mathrm{CaCl}_{2}$ not significant

2. At $\mathrm{t}=30$, Control vs Levo+ $\mathrm{CaCl}_{2}(\mathrm{P}<0.05)$

3. At $\mathrm{t}=40$, Control vs $\mathrm{CaCl}_{2}(\mathrm{P}<0.01)$

Fig. 3 The effects of experimental treatments on systolic blood pressure (mean+SEM) in rats intravenously poisoned with verapamil

$\mathrm{CaCl}_{2}$, and Levo $+\mathrm{CaCl}_{2}$ treatment groups also maintained heart rate at the pretoxicity levels throughout the experiment.

\section{iv) Complications of 4-aminopyridine}

Treatment with 4-AP resulted in onset of generalized muscle fasciculation in all animals in the 4-AP group and the

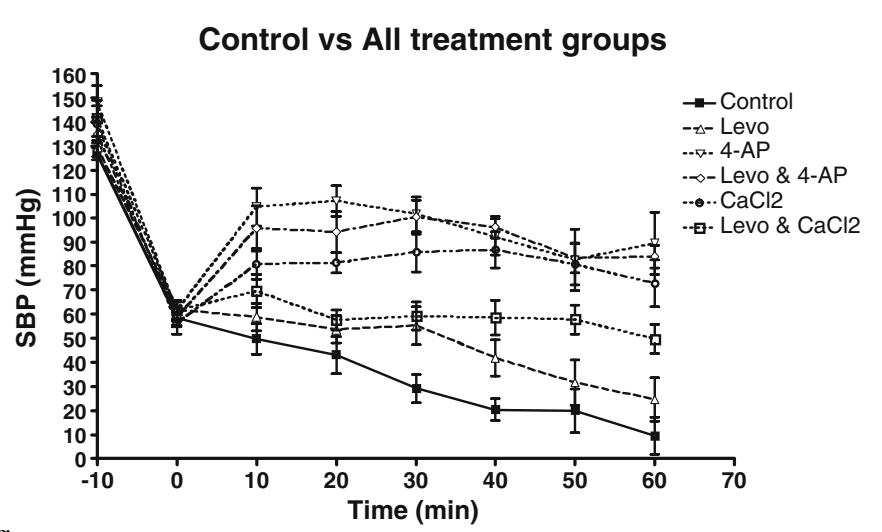

Control vs 4AP

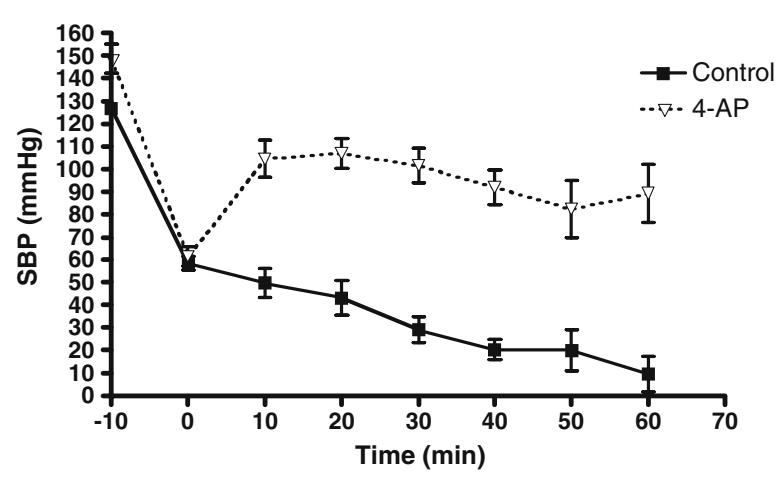

1. At $\mathrm{t}=-10$ and 0 , Control vs $4 \mathrm{AP}$ not significant

2. At $\mathrm{t}=10,20,30,40,50$ and 60 , Control vs $4 \mathrm{AP}(\mathrm{P}<0.01)$

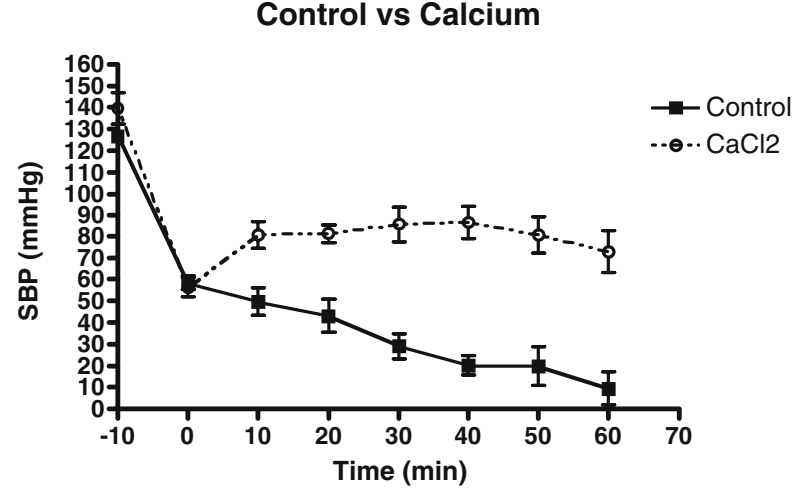

1. At $\mathrm{t}=-10$ and 0 , Control vs $\mathrm{CaCl}_{2}$ not significant

2. At $\mathrm{t}=10$, Control vs $\mathrm{CaCl}_{2}(\mathrm{P}<0.05)$

3. At $\mathrm{t}=20,30,40,50$ and 60 , Control vs $\mathrm{CaCl}_{2}(\mathrm{P}<0.01)$
Levo+4-AP group after the $2 \mathrm{mg} / \mathrm{kg}$ loading dose. During the subsequent continuous infusion of 4-AP, intermittent muscle fasciculation persisted and was also associated with intermittent myoclonic jerking of all four limbs, which was either spontaneous myoclonic or epileptogenic activity, as well as hypersalivation in the animals in these treatment arms. 


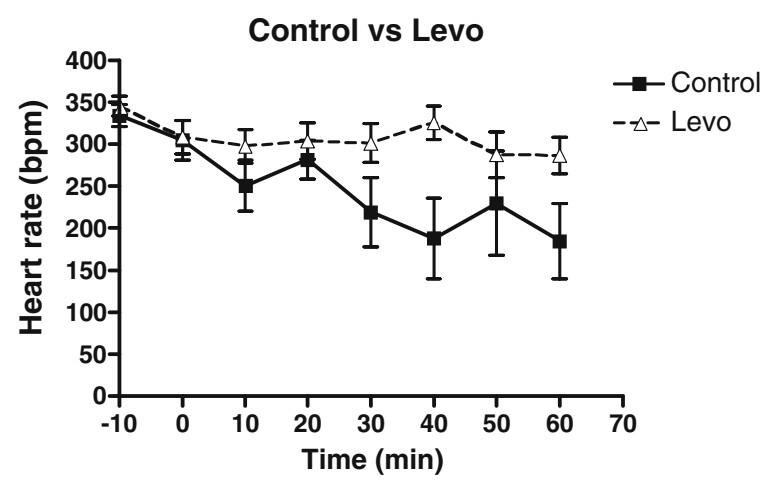

1. At $\mathrm{t}=-10,0,10,20,30$ and 50 , Control and Levo not significant

2. At $\mathrm{t}=40$, Control and Levo $(\mathrm{P}<0.01)$

3. At $\mathrm{t}=60$, Control and Levo $(\mathrm{P}<0.05)$

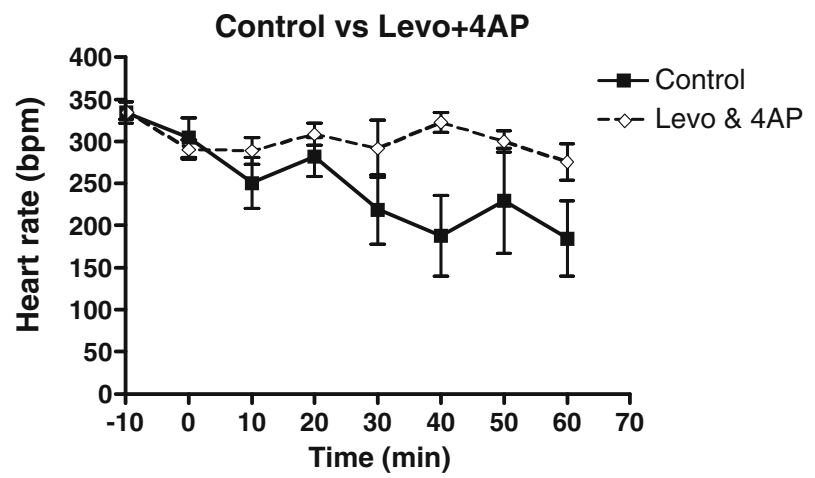

1. At $\mathrm{t}=-10,0,10,20$ and 50, Control and Levo+4AP not significant

2. At $\mathrm{t}=30$ and 60, Control and Levo+4AP $(\mathrm{P}<0.05)$

3. At $\mathrm{t}=40$, Control and Levo+4AP $(\mathrm{P}<0.01)$

\section{Control vs Levo+Calcium}

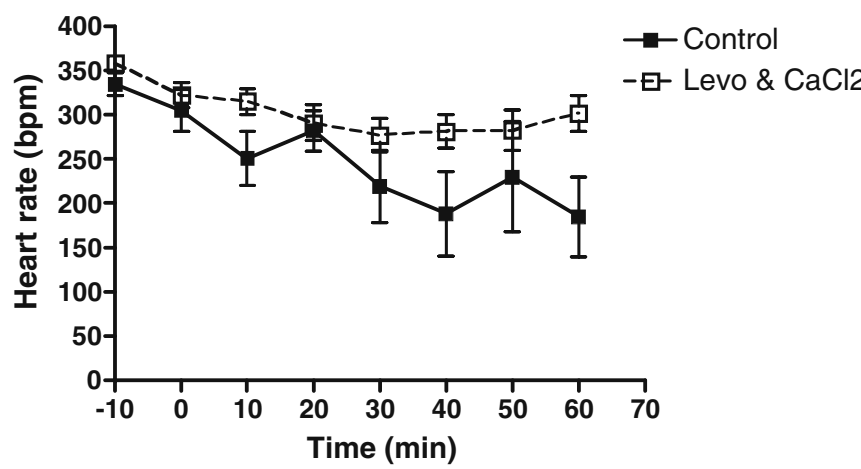

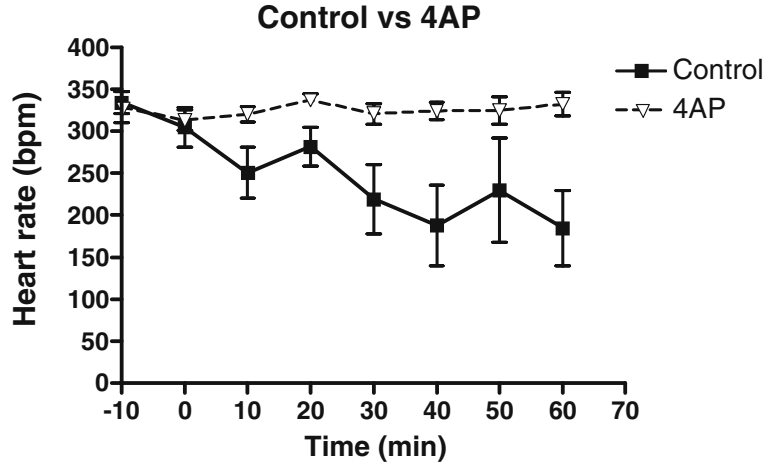

1. At $\mathrm{t}=-10,0,10,20$ and 50, Control and 4AP not significant

2. At $\mathrm{t}=30$, Control and $4 \mathrm{AP}(\mathrm{P}<0.05)$

3. At $\mathrm{t}=40$ and 60 , Control and $4 \mathrm{~A}(\mathrm{P}<0.01)$

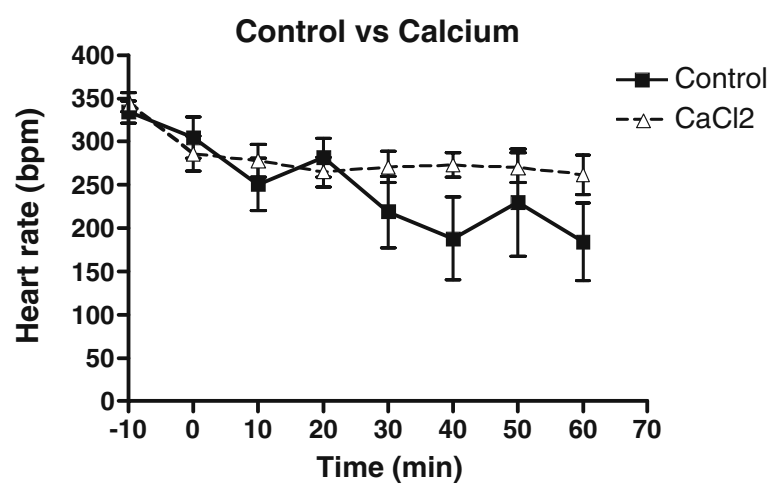

1. At $\mathrm{t}=-10,0,10,20,30,40,50$ and 60 , Control and $\mathrm{CaCl}_{2}$ not significant

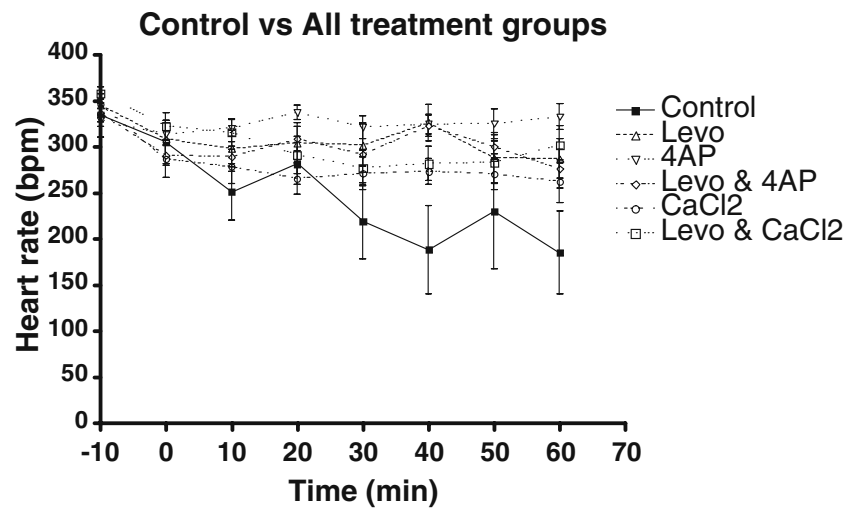

1. At $\mathrm{t}=-10,0,10,20,30$ and 50 , Control and $\mathrm{Levo}+\mathrm{CaCl}_{2}$ not significant

2. At $\mathrm{t}=40$, Control and $\mathrm{Levo}+\mathrm{CaCl}_{2}(\mathrm{P}<0.05)$

3. At $\mathrm{t}=60$, Control and Levo $+\mathrm{CaCl}_{2}(\mathrm{P}<0.01)$

Fig. 4 The effects of experimental treatments on heart rate (mean+SEM) in rats intravenously poisoned with verapamil

\section{Discussion}

The present study confirmed the previous observations of Graudins et al. that levosimendan infusion alone showed a significant improvement in cardiac output when compared to control animals without a significant improvement in blood pressure [4]. Levosimendan is a positive inotropic agent. It has a short half-life of about an hour but is metabolized to an active metabolite, OR-1896, with an elimination half-life of 70-80 h. Levosimendan is currently used for treatment of decompensated heart failure caused by chronic cardiac failure, acute myocardial infarction, and post-cardiac bypass surgery [3,9]. Several studies have demonstrated the benefits of levosimendan in patients after 
cardiopulmonary bypass to enhance their cardiac performance [10]. Levosimendan is also a vascular smooth muscle ATP-potassium channels agonist, which reduces after load and peripheral vascular resistance [11]. From our observations, it appears that the vasodilatory properties of levosimendan may antagonize any benefit in blood pressure that might result from an increase in cardiac output. This suggests that levosimendan might not be an effective inotropic agent in treating verapamil poisoning.

4-Aminopyridine is an investigational drug, which has been suggested as a treatment in a number of neuromuscular disorders including multiple sclerosis, spinal cord injury, Alzheimer's disease, and myasthenia gravis. 4Aminopyridine is a potassium channel antagonist with an indirect influence on calcium channels. It blocks voltagedependent potassium channels on the cytoplasmic side in excitable membranes, leading to accumulation of $\mathrm{K}+$ in the cytoplasm, resulting in rapid depolarization and opening of voltage gated calcium channels [6]. As a result, it is mechanistically appealing in reversal of verapamil poisoning. In a small number of human cases of verapamil intoxication where patients did not respond to calcium, atropine and vasopressor therapy, blood pressure and cardiac rhythm were improved quickly with the addition of 4-aminopyridine infusion [6]. The present study demonstrated that 4-aminopyridine $(2 \mathrm{mg} / \mathrm{kg})$ infusion significantly improved cardiac output and corrected verapamil-induced hypotension compared to control and Levosimendan alone in verapamil poisoned rats. These observations are consistent with previous animal studies assessing the effectiveness of this agent in verapamil poisoning. In a rat model of verapamil overdose, high dose of 4-aminopyridine $(2 \mathrm{mg} / \mathrm{kg})$ infusion improved blood pressure and heart rate, however, low dose 4-aminopyridine $(1 \mathrm{mg} / \mathrm{kg})$ infusion did not significantly increase the HR and MAP at $60 \mathrm{~min}$ and proved to be ineffective in the treatment of experimentally induced verapamil poisoning [12]. In another rat model study, Magdalan demonstrated similar results [6]. 4Aminopyridine $(2 \mathrm{mg} / \mathrm{kg})$ increased blood pressure and heart rate. Moreover, 4-aminopyridine $(2 \times 0.5 \mathrm{mg} / \mathrm{kg}$ IV $)$ reversed cardiodepression and hypotension completely within $50 \mathrm{~min}$ in a cat model of verapamil poisoning [13]. Similarly, 4aminopyridine $(1 \mathrm{mg} / \mathrm{kg})$ produced improvements in heart rate, MAP, and cardiac output in verapamil poisoned dogs [14]. None of the previous studies utilizing rodent models measured the effect of 4-aminopyridine on cardiac output in verapamil poisoning. The response to treatment with 4aminopyridine in animals appears to be dose-dependent. Animals exhibited adverse effects in the above studies as well as in our own study. Muscle twitching and convulsions are known complications of 4-aminopyridine use and despite its beneficial hemodynamic effects in CCB poisoning, these effects may preclude its safe use in humans. Our initial dose finding study, at $1 \mathrm{mg} / \mathrm{kg}$, revealed that this lower dose of 4-aminopyridine did not produce a hemodynamic response in our model of verapamil poisoning. Although 4 -aminopyridine has shown favorable effects on the cardiovascular system in this animal model of verapamil poisoning, significant side effects were observed. These included muscle fasciculation, myoclonus, possible seizure activity and increased oral secretions. These side effects commonly developed after the loading dose and continued during the infusion of 4AP. The epileptogenic action of 4-aminopyridine results from stimulation of glutamic acid release in the central nervous system. Glutamic acid stimulates NMDA receptors to enhance calcium ion influx to neurons, consequently resulting in convulsions. In humans, it has been reported that doses of $0.5-1 \mathrm{mg} / \mathrm{kg}$ may produce hyperexcitability and higher doses may trigger seizure activity [15]. These adverse effects are a significant drawback of using this agent in treatment of clinical verapamil overdose.

Coadministration of levosimendan with 4-aminopyridine did not reveal any added improvement in either cardiac output or blood pressure when compared to 4-aminopyridine alone.

As was seen in our previous study, intravenous calcium chloride infusion produced a significant increase in cardiac output and blood pressure compared to control in this study [4]. However, in the clinical setting of verapamil poisoning, calcium chloride does not result in consistent improvements in hemodynamic function. In verapamil poisoning, L-type calcium channels are blocked and increasing the extracellular calcium concentration may not help to increase the calcium concentration in the cytoplasm [6]. This may explain the transient effect of calcium chloride in the treatment of clinical verapamil poisoning. Alternatively, a lack of response to calcium may be a reflection of an inadequate dose of calcium being administered. In our study, rats received $0.2 \mathrm{mmol} / \mathrm{kg}$. This is a relatively large dose of calcium in a clinical context. We did not measure serum calcium concentrations, but human case reports suggest that increasing serum calcium above physiological reference ranges may improve the response of blood pressure in $\mathrm{CCB}$ poisoning by increasing the extracellular to intracellular calcium concentration gradient [16]. In our study, when levosimendan was coadministered with calcium chloride, cardiac output improved significantly in the first $20 \mathrm{~min}$ and reached the preverapamil toxicity level, but SBP values gradually declined. Similar effects were seen with calcium alone.

\section{Limitations}

The present study was conducted in anesthetized rats, and there is an obvious limitation in application in human subjects. Notably, animals did not develop bradycardia during verapamil infusion despite a drop in blood pressure 
of $50 \%$ from the baseline at the time of initiate treatment. Bradycardia is a significant early feature of human verapamil poisoning but only developed in rats as a preterminal finding. Consequently, the response to levosimendan or 4-aminopyridine in verapamil poisoned rats may differ to that seen in humans. Hence, the result from this study may not truly reflect the actual physiological or pharmacological response seen in humans. Nevertheless, levosimendan has improved cardiac output in both human and animal models of nontoxicological severe heart failure [17]. Moreover, in this poisoning model, rats were administered a continuous infusion of verapamil to simulate continuous GI absorption of the drug from a sustainedrelease ingestion. As a result, a severe degree of toxicity was evoked which may not mimic the pathophysiology of sustained-released ingestion in a real clinical setting. We did not examine the metabolic effects of verapamil poisoning and metabolic responses to the various treatment arms. An assessment of acid-base status, blood glucose and lactate concentrations may have provided additional information on the physiological response to each therapeutic intervention. This was a nonblinded experimental study. Since the investigator knew the treatment groups being administered in every experiment, observer bias may have been introduced into data collection. However, all the data collected in this study was objective hemodynamic data with little opportunity to make subjective interpretations of any response to the various therapies.

Thiobutabarbital is a long-acting barbiturate animal anesthetic, with minimal effects on hemodynamics in cardiovascular animal research [18]. In high doses, it may result in myocardial depression and lower the blood pressure in animals due to central inhibition of the vasomotor center. The doses used in this study were similar to those cited in previous research examining cardiovascular physiology in verapamil poisoned rodents $[4,5,18]$.

\section{Conclusion}

Levosimendan produced moderate improvements in cardiac output in this animal model of verapamil poisoning. The benefits of its positive inotropic effects were negated by a lack of improvement in blood pressure with this agent, most likely related to levosimendan's peripheral vasodilatory effects. We were unable to show any additive effects on cardiac output or blood pressure by coadministration of 4aminopyridine or calcium in the presence of levosimendan. Based on this animal research, extreme caution should be exercised if considering the use of levosimendan in human verapamil poisoning. The vasodilatory effects of this agent may compound the hemodynamic instability seen with calcium channel blocker poisoning and result in worsening of shock in the clinically poisoned patient.

Disclosures Research is funded by a 2007 American College of Medical Toxicology/Orphan Medical Antidote Research Grant.

\section{References}

1. Huang L, Weil MH, Sun S, Cammarata G, Cao L, Tang W (2005) Levosimendan improves postresuscitation outcomes in a rat model of CPR. J Lab Clin Med 146(5):256-261

2. Huang L, Weil MH, Tang W, Sun S, Wang J (2005) Comparison between dobutamine and levosimendan for management of postresuscitation myocardial dysfunction. Crit Care Med 33(3):487-491

3. Lehtonen L (2004) Levosimendan: a calcium-sensitizing agent for the treatment of patients with decompensated heart failure. Curr Heart Fail Rep 1(3):136-144

4. Graudins A, Najafi JM, Perry M (2008) Treatment of experimental verapamil poisoning with levosimendan utilizing a rodent model of drug toxicity. Clin Toxicol 46(1):50-56

5. Najafi JM, Graudins A (2007) Norepinephrine co-administered with levosimendan does not reverse hypotension in a rodent model experimental verapamil poisoning (abstract). Emerg Med Australas 19(Suppl 1):A19-A20

6. Magdalan J (2003) New treatment methods in verapamil poisoning: experimental studies. Pol J Pharmacol 55(3):425-432

7. Magdalan J, Kochman K, Antonczyk A, Przewlocki M, Smolarek M (2003) Successful treatment by 4-aminopyridine of three cases of severe verapamil poisoning. Przegl Lek 60(4):271-273

8. Hill MA, Larkins RG (1989) Alterations in distribution of cardiac output in experimental diabetes in rats. Am J Physiol 257(2 Part 2): H571-H580

9. Follath F (2003) Levosimendan in patients with low-output heart failure: lessons from the LIDO trial. Ital Heart J 4(Suppl 2):34S-38S

10. Nijhawan N, Nicolosi AC, Montgomery MW, Aggarwal A, Pagel PS, Warltier DC (1999) Levosimendan enhances cardiac performance after cardiopulmonary bypass: a prospective, randomized placebo-controlled trial. J Cardiovasc Pharmacol 34(2):219-228

11. Lehtonen LA (2001) Levosimendan: a parenteral calciumsensitising drug with additional vasodilatory properties. Expert Opin Investig Drugs 10(5):955-970

12. Tuncok Y, Apaydin S, Gelal A, Ates M, Guven H (1998) The effects of 4-aminopyridine and Bay K 8644 on verapamil-induced cardiovascular toxicity in rats. J Toxicol - Clin Toxicol 36(4):301-307

13. Agoston S, Maestrone E, van Hezik EJ, Ket JM, Houwertjes MC, Uges DR (1984) Effective treatment of verapamil intoxication with 4-aminopyridine in the cat. J Clin Invest 73(5):1291-1296

14. Gay R, Algeo S, Lee RJ, Olajo M, Morkin E, Goldman S (1986) Treatment of verapamil toxicity in intact dogs. J Clin Invest 77 (6):1805-1811

15. Stork CM, Hoffman RS (1994) Characterization of 4-aminopyridine in overdose. J Toxicol - Clin Toxicol 32(5):583-587

16. Buckley N, Dawson AH, Howarth D, Whyte IM (1993) Slowrelease verapamil poisoning. Use of polyethylene glycol wholebowel lavage and high-dose calcium. Med J Aust 158(3):202-204

17. Slawsky MT, Colucci WS, Gottlieb SS, Greenberg BH, Haeusslein E, Hare J et al (2000) Acute hemodynamic and clinical effects of levosimendan in patients with severe heart failure. Study Investigators. Circulation 102(18):2222-2227

18. Buelke-Sam J, Holson JF, Bazare JJ, Young JF (1978) Comparative stability of physiological parameters during sustained anesthesia in rats. Lab Anim Sci 28(2):157-162 